\title{
Hydrological alteration and biodiversity change along the river network caused by anthropogenic activities and climate variability
}

\author{
Farshid Zolfagharpour ${ }^{1}$, Bahram Saghafian ${ }^{1^{*}}$ and Majid Delavar ${ }^{2}$
}

\begin{abstract}
Background: Population growth and intensified human activities in conjunction with climate variability continue to affect the hydrologic cycle, aquatic and terrestrial flora and fauna. In this regard, understanding interactions among ecosystem functions, impacts of anthropogenic interventions and those of climate variability is vital for projecting future ecosystem responses to human activities and climate forcing. The objectives of this study are to determine the ecological flow state via eco-flow index based on discharge hydrograph, to model the ecological diversity through the Shannon diversity index, and to assess the degree of hydrologic alteration using indicators of hydrologic alteration and range of variability approach in six hydrometric stations along the Zayandeh-Rud River in central Iran. The river drains into Gavkhuni Marsh. Also, the streamflow-induced potential changes for Capoeta damascina (a cyprinid fish species of the genus Capoeta), Petroleuciscus esfahani (a small cyprinid fish) and Aphanius isfahanensis (a Cyprinodontid fish) are evaluated. The outcome is expected to assist managers with understanding the effects of anthropogenic activities and climate variability on Gavkhuni aquatic ecosystems so that management options that enhance species resilience and adaptability are outlined.
\end{abstract}

Results: Human activities, a primary factor influencing the natural flow regime, caused a significant increase in the minimum flow, July to March streamflow, low pulse number, and the number of reversals in most studied stations. On the contrary, some other hydrologic indices declined in value. Reservoir impoundment, the most prominent factor among human interventions, resulted in an overall alteration degree of $74.8 \%$ in streamflow. Climate variability impacted the natural flow regime in the range of low degree hydrologic alteration (27.3\%). In addition, the biodiversity of the study basin, as modeled by the Shannon diversity index, had strong relevance to the annual eco-surplus and was more sensitive to summer floods and autumn hydrological droughts than other factors.

Conclusions: This study corroborates the effectiveness of scenario-based hydrological modeling framework in evaluating the impacts of climate variability and human activities imposed on natural flow metrics. Additionally, the recently introduced eco-flow metrics based on discharge hydrographs and the Shannon diversity index based on indicators of hydrological alteration may be adopted in basins lacking ecological data. These two indices can effectively identify the most prominent factors in hydrological alteration and biodiversity change through a river network and may provide scientific decision-making support for water resource management in the study area.

\footnotetext{
*Correspondence: saghafian@scwmri.ac.ir

${ }^{1}$ Department of Civil Engineering, Science and Research Branch, Islamic

Azad University, Tehran, Iran

Full list of author information is available at the end of the article
}

(c) The Author(s) 2022. Open Access This article is licensed under a Creative Commons Attribution 4.0 International License, which permits use, sharing, adaptation, distribution and reproduction in any medium or format, as long as you give appropriate credit to the original author(s) and the source, provide a link to the Creative Commons licence, and indicate if changes were made. The images or other third party material in this article are included in the article's Creative Commons licence, unless indicated otherwise in a credit line to the material. If material is not included in the article's Creative Commons licence and your intended use is not permitted by statutory regulation or exceeds the permitted use, you will need to obtain permission directly from the copyright holder. To view a copy of this licence, visit http://creativecommons.org/licenses/by/4.0/. 
Keywords: Eco-flow, Shannon diversity index, Human activity, Indicators of hydrologic alteration, Natural flow regime, Range of variability, Zayandeh-Rud River

\section{Introduction}

To date, several natural flow regime paradigms have been proposed that aim to preserve ecosystems. Among them, perhaps, the indicators of hydrologic alteration (IHA) (Richter et al. 1997) have attracted the most attention. The IHA describes the streamflow with various intrinsic characteristics, including the magnitude of monthly flows, magnitude-duration-timing of extreme annual flow, and frequency and duration of high/low flow pulses. The number of IHA parameters reaches 171, 32 of which are rooted in five fundamental features of hydrological regimes.

Evaluating each IHA parameter separately may be a complex task. In such a situation, the hydrologic alteration factor for the holistic assessment of the system state may be used to transform a set of 32 IHA metrics into a single metric for high, medium, and low variability categories based on nonparametric Range of Variability Approach (RVA) analysis (Reichold et al. 2010). Mimicking the pre-impact flow regime to minimize the hydrologic alteration factor in the flow regime and downstream ecosystem supports sustainable watershed development (Reichold et al. 2010; Song et al. 2020). Singh and Jain (2021) used the average squares of the degree of alteration for the 32 IHA parameters to evaluate the overall degree of hydrologic alteration in the flow regime of the Roanoke River and reported a moderate alteration in the riverine ecosystem. Song et al. (2020), using the square root of the average squares of 32 IHA parameters, studied the impact of dams on hydrologic regime changes, considering 35 monitoring stations in China. They concluded that dam operation reduced the IHA parameters except for the extreme minimum flow, December to March streamflow, low pulse number, and the number of reversals. The degree of hydrologic alteration (DHA) may also be computed as the ratio of the difference between the observed frequency (i.e., the observed number of years during a post-dam period wherein the value of a particular hydrologic index lies within the RVA target range) and the expected frequency (i.e., expected number of years during a post-dam period wherein the value of a particular hydrologic index lies within the RVA target range) to the expected frequency (Sharma et al. 2021).

In addition to human activities, climate variability may also affect the hydrological processes by altering evapotranspiration and decreasing total regional water supplies (Sun 2013; Sun et al. 2017) and the DHA within riverine systems (Dong et al. 2019). Dosdogru et al. (2020) used the Soil and Water Assessment Tool (SWAT) model and found that climate change is likely to increase maximum monthly streamflow, especially during the June-September period, which has affected aquatic organisms by altering habitat availability. Usman et al. (2020) showed that hydrologic alteration impacts the fish and migratory bird species. They also indicated an increase in the DHA of all five IHA groups (see Additional file 1: Table S1).

The hydrologic alteration factor framework is complex and data-intensive. Thus, several researchers have sought a simplified form of hydrological impact assessment with a limited number of metrics. In this regard, Vogel et al. (2007) introduced the concept of seasonal eco-deficit/eco-surplus, which may be determined over a given period (e.g., month, season, or year), to evaluate the impact of reservoir regulation on the ecological flow regime. As annual flow duration curves (FDCs) mask the effect of seasonal variations in the river regime, Vogel et al. (2007) used median seasonal FDCs rather than median annual FDCs. Since IHA metrics may be inter-correlated, some studies have assessed the ecoflow metrics. For instance, Gao et al. (2012) compared the ecological flow metrics with the IHA metrics and showed that there is a significant correlation between the IHA metrics and seasonal eco-deficit/eco-surplus. They also concluded that these two sets of metrics could correctly estimate changes in the flow regime. Guo et al. (2021) noted that $75 \%$ seasonal FDC is not a part of the $75 \%$ annual FDC, as they are two curves with different shapes and lengths, which causes inconsistency with the assessment of eco-flow via FDCs on different time scales. Hence, revised eco-flows based on discharge hydrograph were proposed to be used across different time scales. Further, the Shannon diversity index was used to evaluate whether and how eco-deficit and eco-surplus relate to ecosystem conditions.

More than 20 years of continuous historical daily flow data are required to assess river flow regime variation using the IHA/RVA method (Zuo and Liang 2015). With sufficient time series data, the approach allows the calculation of flow features and then the mean flow alteration (Singh and Jain 2021). Regardless of the required time and cost, hydrological models are valuable tools in such studies. For example, the SWAT (Arnold et al. 1998) model has been extensively used in different applications such as: (i) estimation of monthly streamflow; (ii) assessment of climate change and human impacts on streamflow (e.g., Zolfagharpour et al. 2020) in the past, present, 
and future; (iii) simulation of streamflow trend in different scenarios (e.g., Zuo and Liang 2015; Zolfagharpour et al. 2020; Ghaith and Li 2020; Zhang et al. 2020), and (iv) provision of reliable daily streamflow time series for IHA analysis (e.g., Zhang et al. 2020).

The objectives of this study are as follows: (1) to examine the applicability of the newly proposed eco-flow metrics by Guo et al. (2021) based on discharge hydrograph; (2) to model the ecological diversity via the Shannon diversity index and examine its correspondence to ecoflows, and (3) to quantify the impact of anthropogenic activities and climate variability on the degree of hydrologic alteration (DHA) using indicators of hydrologic alteration (IHA) and range of variability approach (RVA) in six hydrometric stations along the Zayandeh-Rud River. The proposed approach in this study paves the way for analysis of the DHA in similar basins with inadequate natural and/or impacted streamflow historical daily data records.

\section{Study area and methodology Study area}

Zayandeh-Rud River Basin (ZRRB), with a total area of $41,500 \mathrm{~km}^{2}$, is located in central Iran. Rangelands are the dominant land cover extending over $60 \%$ of the basin area. The Zayandeh-Rud River runs from west to east into increasingly arid areas, eventually terminating into the Gavkhuni Marsh located some $150 \mathrm{~km}$ east of Isfahan historic city. Direct rain and snowmelt in the upland Zagros mountains are the main sources of water in the Zayandeh-Rud River. The snow depth in the western upland basin area may reach over $4 \mathrm{~m}$. Across the river, the Zayandeh-Rud dam has been operating since 1972 with a modest storage capacity of 1470 million cubic meters (MCM). The highest and lowest altitudes of the basin are 3974 and $1450 \mathrm{~m}$ above mean sea level, respectively. The climate of the ZRRB is quite diverse; the average precipitation in the Koohrang meteorological station located in the western part of the basin is $1361 \mathrm{~mm}$, while in Varzanah station in the eastern part of the basin is only $90 \mathrm{~mm}$. The mean annual temperature in the west altitudes, which are above $2500 \mathrm{~m}$ from mean sea level, reaches $7.6^{\circ} \mathrm{C}$, while in the lowlands it rises to $16.8^{\circ} \mathrm{C}$. The maximum and minimum recorded absolute temperatures in the basin are 43.9 and $-30.6{ }^{\circ} \mathrm{C}$, respectively. The drastic climatic variation within the study basin has created ecological diversity. In general, in ZRRB, there are three specific fish species in both upstream and downstream reaches of the river. The first is Petroleuciscus esfahani (an endemic species with length commonly around $10-12 \mathrm{~cm}$ ), mostly living along the Palasajan upland tributary river (Coad and NG, 2010). The second is Aphanius isfahanensis, an endemic species mainly found in three localities, Varzanah Bridge, Zarrinshahr (a city between Pole-Kalle and Isfahan city), and Gavkhuni Marsh (Keivany 2013). The last one is Capoeta damascina, a native species with the natural locality near Pirbakran city (Asadollah et al. 2011). High temperature in Gavkhuni Marsh has caused hypersaline conditions, which ensures a simple trophic structure and low species diversity biotopes for this ecosystem. Artemia salina is one important crustacean species in Gavkhuni Marsh, which as a simple food chain will provide for the sustainability of Gavkhuni Marsh ecosystem.

Six hydrometric stations from upstream to downstream are Eskandari, Qale-Shahrokh, Pole-Zamankhan, Pole-Kalle, Musian, and Varzanah. The selected stations have the longest data records suitable for assessing the hydrological alteration in the Zayandeh-Rud River. Eskandari station is located on the Palasajan tributary river. It is about $18 \mathrm{~km}$ away from the confluence of the Palasajan River with the main Zayandeh-Rud River. QaleShahrokh is about $62 \mathrm{~km}$ far from the ZRRB divide. The distances between Qale-Shahrokh to Pole-Zamankhan, Pole-Zamankhan to Pole-Kalle, Pole-Kalle to Musian, and Musian to Varzanah hydrometric station are approximately $85,52,64$, and $15 \mathrm{~km}$, respectively.

Figure 1 displays the study area, including the location of the Zayandeh-Rud dam, hydrometric stations, water transfer projects, and main water users. Mainly the Palasajan sub-basin upstream of the Zayandeh-Rud dam makes a significant contribution to the ZayandehRud River streamflow. Three diversion tunnels (e.g., Koohrang-1, Koohrang-2, and Cheshmeh-Langan) have been carrying water into the study basin since 1954, 1986, and 2005, respectively (Fig. 2).

\section{Construction of natural flow regime (NFR)}

The NFR of Zayandeh-Rud River was simulated using SWAT in a previous study (Zolfagharpour et al. 2020). SWAT is a semi-distributed hydrological model that can predict the impact of management practices (i.e., reservoir operation and various land managements) on the hydrologic response of basins (Arnold et al. 1998). There are several parameters in SWAT related to streamflow/ groundwater quantity. The SWAT Calibration and Uncertainty Package (SWAT-CUP) is employed to calibrate and analyze the uncertainty of the specified set of parameters.

Zolfagharpour et al. (2020) quantified the impact of climate variability through a scenario-based hydrological modeling framework using the following procedure: (1) Mann-Kendall trend test to detect a significant trend in the climatic data series; (2) Pettitt test to determine abrupt changes in data series; (3) linear trend removal to detrend the climatic variables; and (4) simulation of the NFR by enforcing the detrended climatic time series into 


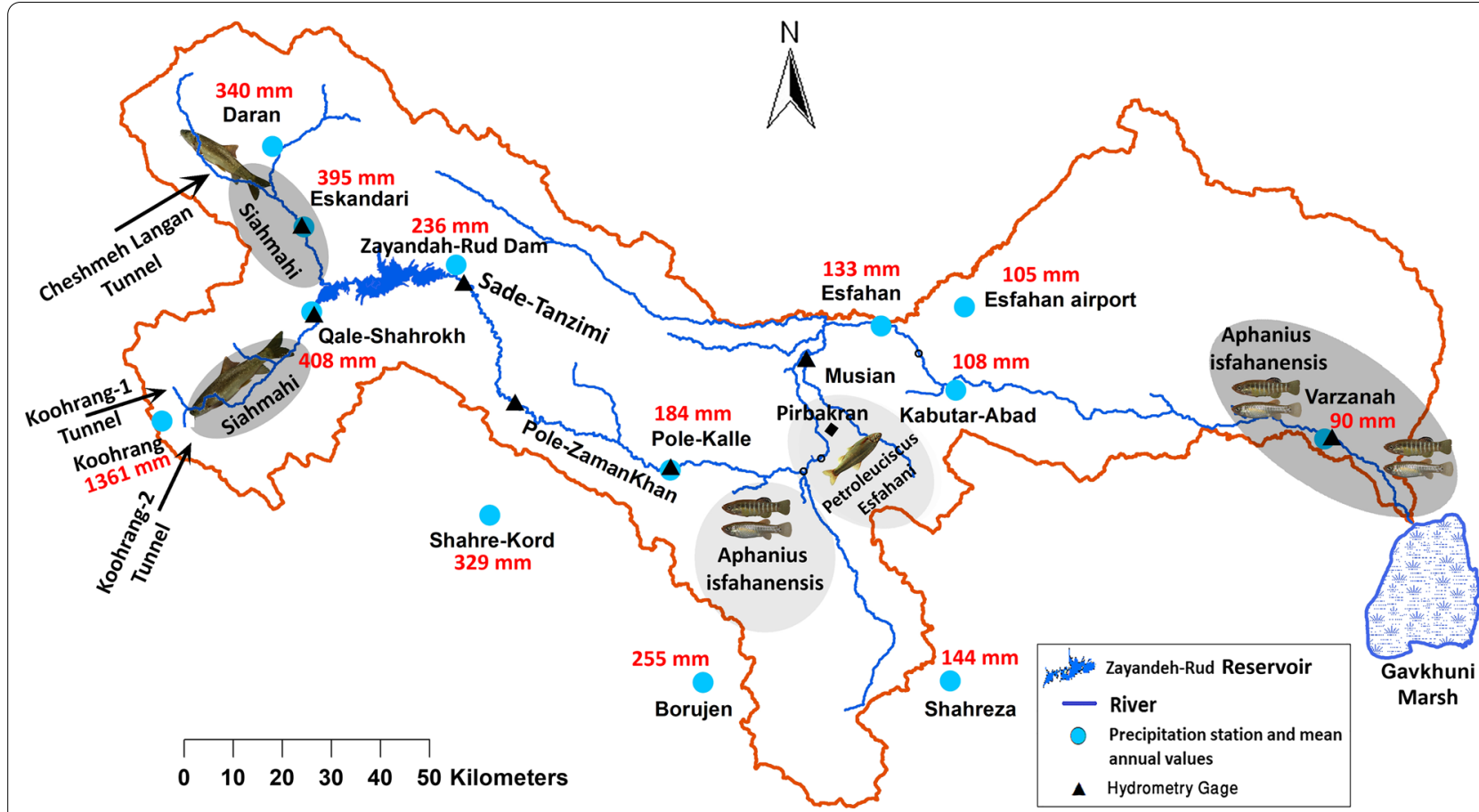

Fig. 1 The study area, main water resources components, mean annual precipitation through the basin (red labels), and the distribution map of the three endemic fish

SWAT. In the present study, the DHA was assessed using the simulated NFR. Zolfagharpour et al. (2020) provide detailed information on the application of SWAT to simulate the NFR in the study basin.

\section{Assessment of hydrologic alteration}

This study took advantage of the IHA to estimate the ecoflow metrics and evaluate the degree of hydrologic alteration. The selected 33 IHA indices (see Additional file 1: Table S1) were used to assess the DHA (Eq. 1) based on 33 interannual statistics between the pre- and postimpact flow in six studied hydrometric stations. These indices were used for the system evaluation over time and to determine the NFR status relative to the current condition. Further, IHA indices of NFR were compared to those of climate variability simulation scenarios.

\section{Degree of flow alteration}

The IHA is representative of changes in the flow regime, and RVA classifies the changes based on the selected RVA targets for water resource management purposes and ensures the targeted flow conditions every year (Richter et al. 1997). The target flow condition may be assigned based upon selected percentile levels (e.g., the 25th to 75th percentile range) or based upon specific deviation from the mean (e.g., the values at \pm 1 standard deviation from the average) of the NFR (Richter et al. 1997).

The DHA associated with the 33 hydrological indicators considering the pre- and post-impact flow was determined at each station as in Eq. 2 below. The $N_{o, m}$ was calculated from the observed number of post-impact years in which the value of the $m$ th hydrologic indicator fell within its target range (25th and 75th percentile of the $m$ th IHA indices). The number of post-impact years equals the number of years the flow has undergone fundamental changes and falls out of the natural flow range. Moreover, $N_{e, m}$ was calculated based on the NFR and is equal to the expected number of post-impact years in which the indicator value fell within the target range:

$$
\begin{aligned}
\mathrm{DHA}_{m, i}= & \left(\left(N_{o, m}-N_{e, m}\right) / N_{e, m}\right) \times 100 \%, i=1,2, \ldots, n \\
& \text { and } m=1 \text { to } 33
\end{aligned}
$$

$$
\begin{gathered}
\operatorname{DFA}_{i}=\sqrt{\sum_{m=1}^{33} \frac{\mathrm{DHA}_{m, i}^{2}}{33}}, i=1,2, \ldots, n \\
\operatorname{DFA}(m)=\left(\frac{1}{n}\right) \sum_{i=1}^{n} \mathrm{DFA}_{i} \quad, i=1,2, \ldots, n
\end{gathered}
$$




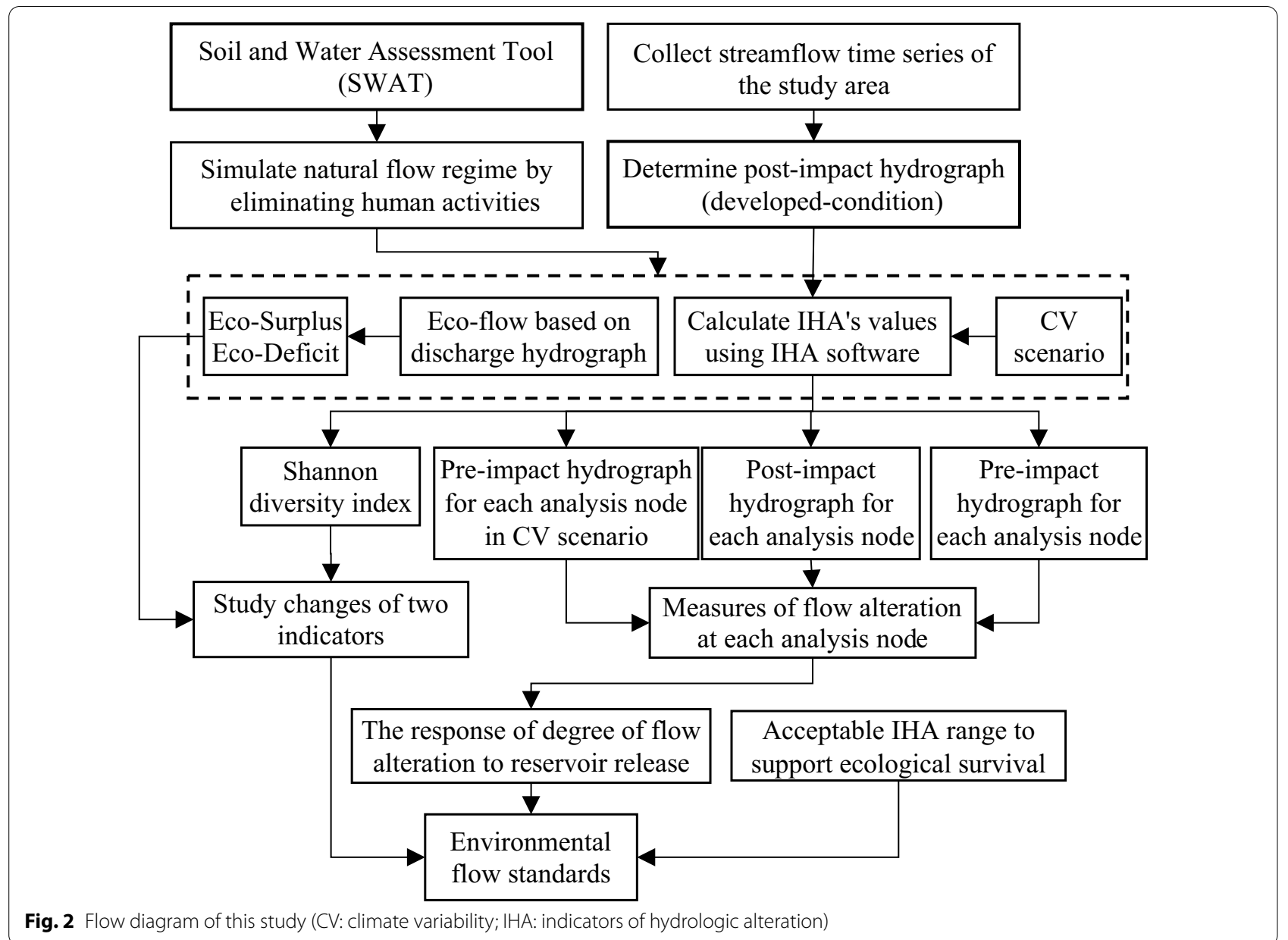

where 33 represents the number of hydrologic indicators and $\mathrm{DHA}_{m, i}$ is the degree of hydrologic alteration in the $i$ th hydrometric station along the Zayandeh-Rud River. To use the hydrologic alterations calculated by Eq. 1 in the planning phase, all the values of $\mathrm{DHA}_{m, i}$ may be aggregated into one representative metric as in Eq. 2. $\mathrm{DFA}_{i}$ is the overall degree of flow alteration in the $i$ th hydrometric station, and DFA $(m)$ is the mean degree of flow alteration in the flow regime throughout the ZRRB. As Varzanah hydrometric station is the most downstream terminal station of the Zayandeh-Rud River, its characteristics represent important metrics for preserving the Gavkhuni Marsh. The IHA software was employed to calculate all 33 IHA metrics for each hydrometric station along the Zayandeh-Rud River.

\section{Eco-flow index based on discharge hydrograph}

As in the newly eco-flow index proposed by Guo et al. (2021), the daily discharge hydrograph of each year was used to calculate the $25 \%$ and the $75 \%$ discharge hydrographs and obtain the lower and upper limits of the river management target range (Fig. $3 \mathrm{~A}$ and $\mathrm{B}$ ). The eco-deficit (ED) and eco-surplus (ES) may be computed over any period of interest (month, season, or year) and reflect the overall loss or gain, respectively, in streamflow during the period that results from flow regulation. The total area below the unregulated discharge hydrograph and above the regulated discharge hydrograph determines the ED, the net volume of unavailable water to meet instream flow requirements. Conversely, the total area above the unregulated discharge hydrograph and below the regulated discharge hydrograph is termed ES. The maximum and minimum seasonal ecological water requirements are also defined. The division into seasons is made a priori according to the calendar seasons, winter, spring, summer, and autumn. Taking the winter as an example, the total area below $75 \%$ and $25 \%$ discharge hydrograph over January 1 to March 31 measures the winter maximum and minimum ecological water requirements, respectively. The 

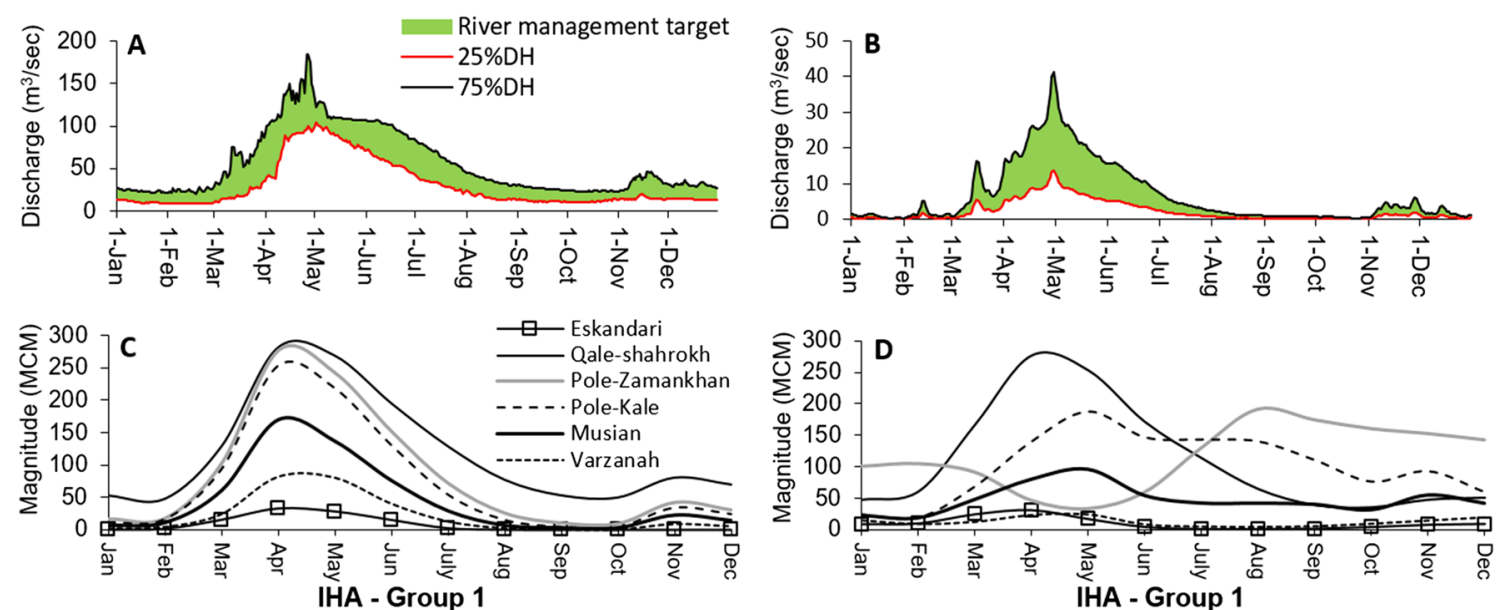

Fig. 3 A River management targets for Qale-Shahrokh station; B river management targets for Varzanah station; C magnitude of monthly natural flow regime along the Zayandeh-Rud River; $\mathbf{D}$ post-dam flow condition

seasonal and the annual eco-surplus $\left(\mathrm{ES}_{s}\right.$ and $\left.\mathrm{ES}_{a}\right)$ and eco-deficit $\left(\mathrm{ED}_{s}\right.$ and $\left.\mathrm{ED}_{a}\right)$ values are defined as follows:

$$
\begin{aligned}
& \text { If }\left\{\begin{array}{l}
Q_{i}>Q_{i}^{75 \%} \rightarrow \mathrm{ES}_{s}=\frac{t \sum_{i=1}^{n}\left(Q_{i}-Q_{i}^{75 \%}\right)}{\operatorname{Max} W_{s}},(s=1,2,3,4) \\
Q_{i}<Q_{i}^{25 \%} \rightarrow \mathrm{ED}_{s}=\frac{t \sum_{i=1}^{n}\left(Q_{i}-Q_{i}^{25 \%}\right)}{\operatorname{Min} W_{s}},(s=1,2,3,4)
\end{array},\right. \\
& \mathrm{ES}_{a}=\sum_{s=1}^{4} \mathrm{ES}_{s}, \\
& \mathrm{ED}_{a}=\sum_{s=1}^{4} \mathrm{ED}_{s},
\end{aligned}
$$

where $s$ denotes the season ( $s=1$ for spring, and so on); $t=86,400 \mathrm{~s} ; n$ is the number of days in each season ( $n=92$ for spring, and so on); and $Q_{i}^{75 \%}$ and $Q_{i}^{25 \%}$ denote the $75 \%$ and $25 \%$ discharge of each day, respectively. The Max $W_{s}$ and $\operatorname{Min} W_{s}$ indicate the total seasonal surplus and deficient instream flow, respectively. $\mathrm{ES}_{S}$ and $\mathrm{ED}_{S}$ values represent the percentage of runoff exceeding the $\operatorname{Max} W_{S}$ divided by $\operatorname{Max} W_{S}$, and lower than $\operatorname{Min} W_{S}$ divided by $\operatorname{Min} W_{S}$, respectively. $\mathrm{ES}_{S}$ is positive, while $\mathrm{ED}_{S}$ is negative.

\section{Ecological diversity}

To validate the suitability of eco-flows in representing the ecological condition of a basin, Guo et al. (2021) used a diversity index as the basis to evaluate how and to what extent the eco-flows follow the Shannon diversity index. Natural communities have a higher diversity index. As the number of species and total individuals in the community increase, with a more evenly distributed population of various species in the community, the diversity index will enhance (Pielou 1975). The most commonly used diversity index is the Shannon Index (Shannon 1948) and can be estimated by the equation: $H=-\sum_{i} p_{i} \times \log \left(p_{i}\right)$, where $p_{i}$ is the proportion of the community belonging to the $i$ th species. The Shannon diversity index has been used widely in stream ecology studies as a quick and reliable tool to identify main changes in community structure (Pettersson 1998). In this study, Eq. 7 was used for modeling Shannon Index values. Equation 7 was developed by genetic programming using data from a different riverine system for hydrologic stations without field data (Yang et al. 2008) which links between IHA metrics and Shannon diversity index as follows:

$$
H=\frac{\left(D_{\min } /\left(D_{\min }+Q_{3}+Q_{3 \text { day }}^{\max }\right)\right)}{Q_{5}+Q_{1 \text { day }}^{\min }+Q_{7 \text { day }}^{\min }+Q_{7 \text { day }}^{\max }}+R_{\text {rate }}
$$

where $Q_{3}$ and $Q_{5}$ are the average discharge in March and May, respectively; $Q_{3 \text { day }}^{\max }$ and $Q_{7 \text { day }}^{\max }$ are the annual maximum average 3-day and 7-day discharges; $Q_{1 \text { day }}^{\text {min }}$ and $Q_{7 \text { day }}^{\text {min }}$ are the annual minimum average 1-day and 7-day discharges; $D_{\min }$ is the Julian date of annual minimum daily flow, and $R_{\text {rate }}$ is the mean of all positive differences between consecutive daily flow. The increase of $D_{\min }$ and $R_{\text {rate }}$ has a positive contribution to Shannon diversity index, whereas $Q_{5}$ has a negative impact on the index.

\section{Results}

\section{Assessment of natural flow condition}

The study basin has long been subject to anthropogenic activities via excessive water consumption, regulation of streamflow, and disregard to the eco-flow. SWAT was adopted to simulate the NFR by eliminating the impact 
of dam, agricultural, municipal and industrial water consumptions while ignoring interbasin water transfers (Fig. 3C). Compared to the observed streamflow during the post-dam period (Fig. 3D), the simulated NFR showed a different monthly pattern signifying the impact of human activities in the basin.

\section{Streamflow variability and monthly flow conditions (IHAs' group 1)}

The spatiotemporal changes in the NFR and observed runoff characteristics along the Zayandeh-Rud River based on the Eskandari, Qale-Shahrokh, PoleZamankhan, Pole-Kalle, Musian, and Varzanah stations' time series were determined (Fig. 3). Pole-Kalle and Varzanah hydrometric stations had sufficiently long daily streamflow records before and after the construction of the Zayandeh-Rud dam. So, the IHAs could assess the impact of pre- vs. post-dam periods and the impact of transboundary water transfer projects. The mean annual runoff of Pole-Kalle during the pre-dam (1961-1971) and post-dam (1972-2013) periods were 838.3 and 1233.3 MCM, respectively. Similar values are equal to 94.1 and 158.9 MCM at Varzanah station, respectively.

The western upstream branch of the Zayandeh-Rud River joins the Eskandari River and then enters the Zayandeh-Rud reservoir. On average, Qale-Shahrokh hydrometric station receives $1334.3 \mathrm{MCM}$ of water annually. This value is $101 \mathrm{MCM}$ less than the mean NFR in this station $(\mathrm{NFR}=1435.23 \mathrm{MCM})$. However, the measured streamflow in Eskandari station, located on the 2nd main right-side tributary of the Zayandeh-Rud River, experienced a $20.02 \%$ increase over its NFR (mean annual $\mathrm{NFR}=98.5 \mathrm{MCM}$ vs. mean annual impacted flow $=118.2$ MCM). This increase is due to the additional water transfer from the Cheshmeh-Langan tunnel. Thus, the yearly average NFR into the Zayandeh-Rud reservoir equals 1534.8 MCM (the time series varied from 365 to 2770.3 $\mathrm{MCM}$ ), which showed a slight reduction of about 5.3\%, compared with the post-impact streamflow. Over the same period, the streamflow of the Varzanah station (observed 158.9 MCM during the post-dam period versus NFR 266.4 MCM) experienced a 40.3\% reduction. The DFA at this station was quite severe during the postdam period $(\approx 76.4 \%)$.

Furthermore, the climate variability scenario showed that during 29 years of the study period (1985-2013), the climatic drivers decreased the inflow into the Zayandeh-Rud dam by 106.4 MCM/year (see Additional file 1: Table S2). This reduction is firstly due to a decrease in precipitation, and secondly, an increase in minimum and maximum temperature caused an increase in the evapotranspiration in the study basin. The SWAT model output indicates that a $1{ }^{\circ} \mathrm{C}$ increase in the mean daily temperature will result in a $42.4 \mathrm{~mm}$ increase in the average annual potential evapotranspiration (over 19852013) at the Palasajan sub-basin, located upstream of the dam. Also, 0.9 and $0.26{ }^{\circ} \mathrm{C}$ increases in the maximum and minimum temperatures caused by climate variability have raised the potential and actual evapotranspiration of the Palasajan sub-basin by 54 and $46 \mathrm{~mm}$, respectively. Additionally, the results show that climate change has inflated the ratio of potential and actual evapotranspiration to precipitation by $8 \%$. As anticipated, the PoleZamankhan and Pole-Kalle, downstream stations on the Zayandeh-Rud River, experienced more reduction in the total annual streamflow.

The streamflow characteristics in the Eskandari and Qale-Shahrokh hydrometric stations were similar as they were not affected by the Zayandeh-Rud dam operation. From July to March, $83 \%$ of the stations recorded a rising trend, e.g., the mean monthly streamflow increased by $28,26,20,45,76,71,49,63$, and $48 \mathrm{MCM}$ during the post-impact periods, respectively. Pole-Zamankhan experienced the most significant change, where impoundment by the Zayandeh-Rud dam increased the mean dry period flow from 2.5 to 186.9 MCM in September. On the contrary, the flow records associated with the QaleShahrokh were still decreasing in the dry season. In April and May, all stations had a consistent decreasing trend. A similar trend existed in five out of six stations in June. However, the maximum reduction that occurred in April and May was equal to 227.6 MCM. The average reduction rates in April, May, and June were relatively high, which they were equal $61 \%, 59 \%$, and $46 \%$, respectively. However, generally, flows from January through March and July through December increased during the post-dam period. Considering the sum of mean monthly values, four out of six stations (e.g., Eskandari, Pole-Zamankhan, Pole-Kalle, and Musian) experienced more overall positive changes than negative changes (Table 1).

The climate variability decreased the inflow into the Zayandeh-Rud dam with a minimum of $1 \mathrm{MCM} /$ month in March and a maximum of $28.3 \mathrm{MCM} /$ month in June (Additional file 1: Table S2). Assessment of the climate variability scenario showed that the changes in the monthly median streamflow would be decreasing in March, April, May, June, and July by $24.5 \%, 3.6 \%, 3 \%$, $27 \%$, and $11.8 \%$ at Musian station, and by $2.1 \%, 3.5 \%$, $2.2 \%, 5 \%$, and $8.2 \%$ at Varzanah station, respectively. The results indicated a significant decrease in streamflow during June and July in the climate variability scenario.

\section{Magnitude and duration of annual extreme flow conditions}

Annual extreme minimum flows had the same increasing trend in five out of six stations (Additional file 1: 
Table 1 The changes of natural flow regime relative to the post-impact period (in MCM)

\begin{tabular}{|c|c|c|c|c|c|c|c|c|c|c|c|c|c|c|}
\hline Station & Jan & Feb & Mar & Apr & May & Jun & July & Aug & Sep & Oct & Nov & Dec & OPC $^{*}$ & $\mathrm{ONC}^{* *}$ \\
\hline " & 7.6 & 8 & 7.0 & -11.1 & -13.1 & -11.5 & 0.2 & 0.2 & 0.2 & 2.8 & 5.8 & 7.6 & 9.8 & -35.7 \\
\hline Qale-Shahrokh & -6.4 & 11.9 & 47.4 & -7.3 & -37.5 & -18.7 & -5.9 & -15.3 & -11.3 & -13.7 & -19.4 & -18.5 & 59.3 & -153.9 \\
\hline Pole-Zamankhan & 89.7 & 89.6 & 25.1 & -227.6 & -227.6 & -89.2 & 77.8 & 168.1 & 184.4 & 168.3 & 154.5 & 142.1 & 1099.6 & -544.4 \\
\hline Pole-Kalle & 16.0 & 15.6 & 41.6 & -110.5 & -52.4 & 37.3 & 115.0 & 162.0 & 121.0 & 52.8 & 100.4 & 51.1 & 675.6 & -125.6 \\
\hline Musian & 18.9 & 13.8 & 26.0 & -71.3 & -39.0 & -10.5 & 32.8 & 48.2 & 46.6 & 20.3 & 51.6 & 33.9 & 292.2 & -120.8 \\
\hline arzanah & 5.4 & 3.5 & 0.9 & -73.1 & -78.7 & -42.1 & 0.3 & 0.9 & 0.9 & 1.1 & 2.1 & 3.3 & 18.6 & -193.9 \\
\hline
\end{tabular}

*Overall positive changes; ${ }^{* *}$ overall negative changes

Table S3). The average decrease of extreme maximum flows was greater than the mean net increase of extreme minimum flows. The average of the 1-day through 90-day minimum flow duration increased; the 90-day minimum flow exhibited the most significant change $(0.634 \mathrm{MCM})$, and the 1-day minimum flow the smallest (0.184 MCM). The annual minimum/maximum flows did not show a consistent increasing/decreasing trend at Qale-Shahrokh hydrometric station. The average reduction of the 30-day extreme maximum flow was $75.2 \%$, while for the 7 - and 90-day maximum flow was $56.2 \%$, with an average of $36 \%$. Also, a rising trend existed in the base flow index in all stations.

Under the climate variability scenario, the 1- to 90-day average annual minimum flows at Eskandari, Pole-Kalle, Musian, and Varzanah stations showed substantial variations. The climate variability scenario indicated that $1-$ to 90-day mean annual minimum flows decreased at QaleShahrokh, Pole-Zamankhan, and Musian stations, while increased at Eskandari and Varzanah stations. Regarding the Pole-Kalle station, 1- and 3-day minimum flows increased while 7- to 90-day minimum flows decreased (see Additional file 1: Table S3). Moreover, the 1- to 90-day mean annual maxima was reduced at Eskandari and Musian stations. The Qale-Shahrokh and Pole-Kalle results were similar, so that 1 -day maxima increased by $12.6 \%$ and $0.7 \%$, respectively, while 3 - to 90 -day maxima declined.

\section{Timing of annual extreme flows}

The timing of 1-day maximum and minimum flows moved earlier at four out of six stations (Table 2). For 1-day minimum flow, the largest change occurred at Musian by shifting from day 252 to day 54. At PoleZamankhan station, the delay for the 1-day minimum flow timing was 77 days. At Eskandari, Qale-Shahrokh, Pole-Kalle, and Varzanah stations, the date moved up 44 days (from 280th day to the 236th day), 76 days (from 39 th day to the 328th day), 46 days (from 57 th day to the 11th day), and 24 days (from 261st day to the 237th day), respectively. In general, the mean minimum flow timing at two stations was delayed by 122 days relative to the pre-impact period, while the mean timing was 48 days earlier at the remaining stations. In contrast, the deviation of 1-day maximum flow timing was the least. The change in 1-day maximum flow dates was the greatest at Pole-Zamankhan station, shifting from day 105 to 246. The mean maximum flow timing occurred 69 days later at three stations and 23 days earlier at the remaining stations compared to those of the pre-impact period. Overall, the impact on 1-day minimum flow timing was greater than that of maximum flow (Table 2). Julian dates of maximum and minimum varied substantially under the climate variability scenario. In particular, the minimum flow of Qale-Shahokh, Pole-Zamankhan, Musian, and Varzanah stations occurred 12, 1, 41, and 29 days earlier, respectively, compared to those of the climate variability scenario. However, minimum flow at Eskandari and Pole-Kalle stations occurred 73 and 21 days later, respectively.

\section{Frequency and duration of high and low pulses}

The low pulse count was reduced at five stations and increased at one station (Table 2), with a mean increase rate of $34 \%$ and a mean decrease rate of $100 \%$ (Fig. 4). At Musian station, low pulse duration decreased from 56.8 to 17.0. Five out of six stations recorded a decreasing trend for low/high pulse count and low pulse duration. The decrease of low pulse duration was on average 28.8, which ranged from 39.8 (at Musian station) to 14.3 (at Eskandari station). The high pulse count declined at five stations, with a mean decrease of 1.2 and a smaller deviation relative to the low pulse count. Evaluating high pulse duration, four stations showed a reduction, two stations showed an increase, and on average, the reduction was greater than the increase. A significant reduction was observed at Varzanah station by 18.8 . The average increase was 3.2 , while the mean reduction was 11.1 . In general, the mean change in the low pulse count was the greatest, reaching $100 \%$. However, the reductions concerning low pulse duration, high pulse count, and high pulse duration were $78.8 \%, 40.7 \%$, and $46.4 \%$, respectively (Table 2). 
Table 2 Group 3, 4 and 5 of IHA parameters for natural flow regime, post-impact flow regime and flow regime under the impact of climate variability

\begin{tabular}{|c|c|c|c|c|c|c|c|c|c|c|}
\hline & \multirow[t]{3}{*}{ Station } & \multirow{2}{*}{\multicolumn{2}{|c|}{$\frac{\text { Group } 3}{\text { Date of }}$}} & \multicolumn{4}{|c|}{ Group 4} & \multicolumn{3}{|l|}{ Group 5} \\
\hline & & & & \multicolumn{2}{|c|}{ Low pulse } & \multicolumn{2}{|c|}{ High pulse } & \multirow[t]{2}{*}{ Rise rate } & \multirow[t]{2}{*}{ Fall rate } & \multirow{2}{*}{$\begin{array}{l}\text { Number of } \\
\text { reversals }\end{array}$} \\
\hline & & Minimum & Maximum & Count & Duration & Count & Duration & & & \\
\hline \multirow[t]{6}{*}{ Natural flow regime } & Eskandari & 280 & 121 & 1 & 20.3 & 3 & 17 & 0.02 & 0 & 87 \\
\hline & Qale-Shahrokh & 39 & 105 & 3 & 9.5 & 4 & 5 & 0.8 & -0.7 & 112 \\
\hline & Pole-Zamankhan & 51 & 105 & 2 & 22 & 4 & 5 & 0.53 & -0.7 & 115 \\
\hline & Pole-Kalle & 57 & 105 & 2 & 33 & 4 & 5 & 1.34 & -1.01 & 77 \\
\hline & Musian & 252 & 106 & 1 & 56.8 & 5 & 4.5 & 1.63 & -0.7 & 52 \\
\hline & Varzanah & 261 & 114 & 1 & 62 & 2 & 26 & 0.34 & -0.06 & 32 \\
\hline \multirow[t]{6}{*}{ Post-impact flow regime } & Eskandari & 236 & 96 & 0 & 6 & 2 & 13.5 & 0.21 & -0.24 & 56 \\
\hline & Qale-Shahrokh & 328 & 96 & 4 & 18 & 3 & 7 & 1.7 & -1.4 & 90 \\
\hline & Pole-Zamankhan & 128 & 246 & 0 & 1 & 3 & 8.25 & 1.12 & -1.1 & 150 \\
\hline & Pole-Kalle & 11 & 153 & 0 & & 4 & 6 & 1.38 & -1.4 & 174 \\
\hline & Musian & 54 & 125 & 0 & 17 & 4 & 11 & 0.9 & -0.89 & 125 \\
\hline & Varzanah & 237 & 79 & 0 & 26 & 0 & 7.25 & 0.13 & -0.12 & 76 \\
\hline \multirow[t]{6}{*}{ Climate variability scenario } & Eskandari & 207 & 121 & 3 & 20.5 & 3 & 18 & 0 & 0 & 84 \\
\hline & Qale-Shahrokh & 51 & 113 & 2 & 14.5 & 3 & 5.8 & 0.7 & -0.7 & 121 \\
\hline & Pole-Zamankhan & 52 & 116 & 2 & 17.3 & 3 & 5 & 0.6 & -0.8 & 116 \\
\hline & Pole-Kalle & 36 & 113 & 2 & 31.8 & 4 & 5 & 0.7 & -0.5 & 92 \\
\hline & Musian & 293 & 113 & 1 & 61.5 & 5 & 4 & 0.5 & 0 & 61 \\
\hline & Varzanah & 290 & 120 & 2 & 62 & 2 & 25.5 & 0 & 0 & 38 \\
\hline
\end{tabular}

In the climate variability scenario, the low pulse count decreased at Qale-Shahrokh station and increased at Eskandari station, while there were no changes in the other four stations. The high pulse rate decreased at Qale-Shahrokh and Pole-Zamankhan stations while no changes occurred at other stations. The low pulse duration varied by $1.2 \%, 52.6 \%,-21.6 \%,-3.8 \%$, and $8.4 \%$ at Eskandari, Qale-Shahrokh, Pole-Zamankhan, Pole-Kalle, and Musian stations, respectively. Furthermore, the alteration of high pulse duration was $5.9 \%, 15 \%,-11.1 \%$, and - $1.92 \%$ at Eskandari, Qale-Shahrokh, Musian, and Varzanah hydrometric stations, respectively.

\section{Rate and frequency of flow condition}

Rise rates decreased at Musian and Varzanah stations by 62,640 and $18,792 \mathrm{~m}^{3} /$ day, respectively, and increased on average $36,947 \mathrm{~m}^{3} /$ day at other stations ranging from 3024 (at Pole-Kalle) to $77,760 \mathrm{~m}^{3} /$ day (at Qale-Shahrokh). The increase reached $830 \%$ at Eskandari station on one of the important tributaries of the Zayandeh-Rud River. Nevertheless, the increase was lower at Pole-Zamankhan $\left(50,803 \mathrm{~m}^{3} /\right.$ day $)$ than that of Qale-Shahrokh station. The percentage of change $(110 \%)$ was similar at both stations. At Pole-Kalle station (the hydrometric station downstream of Pole-Zamankhan), the change (3\%) was negligible, as considerable water is consumed before the streamflow reaches this station. For the fall rate, the reduction rate varied from $5357 \mathrm{~m}^{3} /$ day at Varzanah to $60,480 \mathrm{~m}^{3} /$ day at Qale-Shahrokh, with an average of $28,521 \mathrm{~m}^{3} /$ day. In contrast, the number of reversals indicated different change patterns. Of the four stations with increasing trends (average $=62.3$ ), the greatest change was at Pole-Kalle station, increasing from 77 to 174 . The second-largest change was associated with the Musian station, ranging from 52 to 125 . Negative changes at Eskandari and Qale-Shahrokh stations were 31 and 22, respectively. In general, the deviation in the rise rate decrease was greater than the fall rates decrease (Table 2). Under climate variability scenario, only at PoleZamankhan station, the median values of rising rates declined by $11.8 \%$. At this station, the median values of fall rates decreased by $10.9 \%$. All other stations demonstrated decreasing and increasing patterns for rising and fall rates, respectively.

\section{Degree of hydrologic alteration}

The alteration degree of 32 IHAs varied substantially among the studied stations. Based on the spatial distribution, low, moderate, and high alterations occurred in each of the 32 IHAs, and the values were significantly different. In general, the IHA mean absolute alteration degree, with an average of $68 \%$, is placed within the 


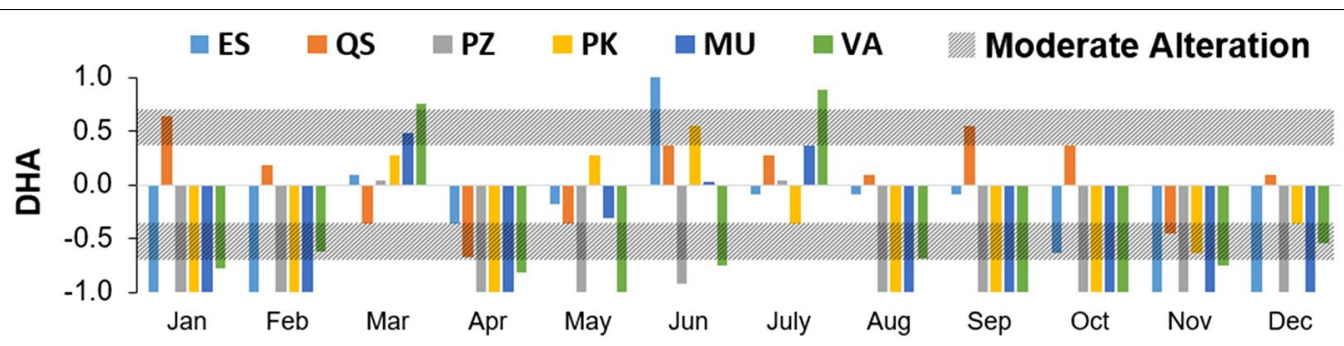

IHA - Group 1
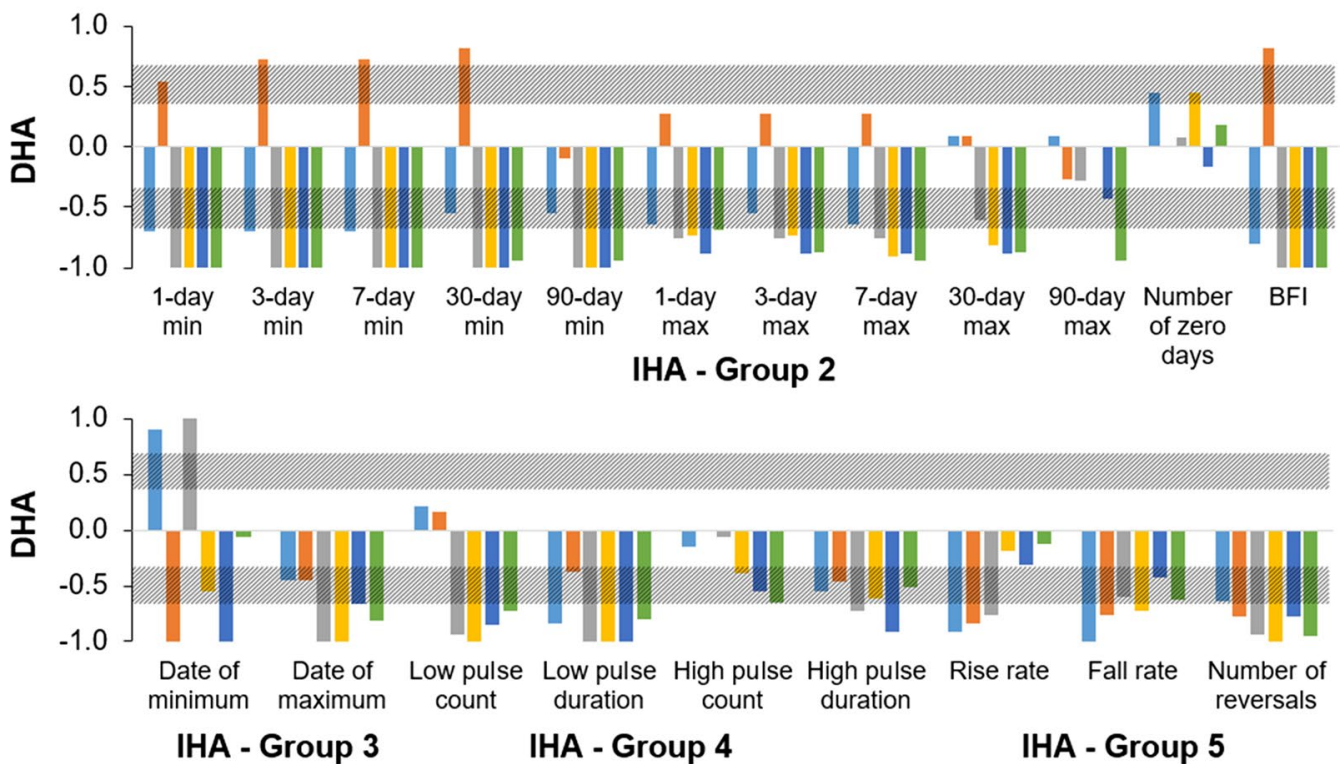

Fig. 4 Degree of hydrologic alteration (DHA) along the Zayandeh-Rud River (HAB: High alteration boundary, LAB: Low alteration, ES: Eskandari, QS: Qale-Shahrokh, PZ: Pole-Zamankhan, PK: Pole-Kalle, MU: Musian, VA: Varzanah)

range of $22 \%$ (low alteration) to $94 \%$ (high alteration). Concerning the average alteration, the base flow index had the greatest alteration with $94 \%$ degree, followed by 3-day minimum flow, 7-day minimum flow, January flow, and 30- and 1-day minimum flows. On the contrary, the smallest mean alteration degrees corresponded to the number of zero flow days, high pulse count, 90-day maximum flow, March flow, and July flow (Fig. 4). The DFA of each station was calculated. DHAs in Pole-Zamankhan, Musian, Pole-Kalle, and Varzanah stations were $87.8 \%$, $83.5 \%, 80.3 \%$, and $80.3 \%$, respectively, which were classified as high alteration. The Eskandari and Qale-Shahrokh stations (located upstream of the Zayandeh-Rud dam) recorded moderate alteration, with $66.5 \%$ at Eskandari and $50.7 \%$ at Qale-Shahrokh.

As the climate variability scenario determines the simulated NFR with the detrended climatic series, almost all the alterations were in the range of low alteration $(0-33 \%)$. High alterations $(67-100 \%)$ occurred for 1 - to 7-day minimum flow at Musian station, 30-day minimum flow at Pole-Zamankhan station, date of minimum flow and fall rate at Musian station, low pulse duration at Eskandari and Pole-Zamankhan stations, and rise rate at Pole-Kalle and Musian stations. None of the hydrologic parameters in the IHA group 1 lie within the high alteration class under the climate variability scenario (see Additional file 1: Fig. S2).

\section{Eco-flows based on discharge hydrographs}

Figure 5 shows the seasonal eco-flows in Pole-Kalle (1962-2013), Varzanah (1962-2013), and Qale-Shahrokh (1985-2013) stations. Overall, in Qale-Shahrokh and Varzanah stations, all of the large $\mathrm{ES}_{S}$ values in each season occurred after constructing of Zayandeh-Rud dam. In the Qale-Shahrokh hydrometric station, 59\%, 21\%, $55 \%$, and $17 \%$ of the years experienced zero $\mathrm{ED}_{S}$ values during winter, spring, summer, and autumn, respectively, while non-zero $\mathrm{ED}_{S}$ values in winter were small. In the other three seasons, all large $\mathrm{ED}_{S}$ values occurred during the 2008-2013 period.

In Pole-Kalle station, the impact of the dam reduced the $\mathrm{ES}_{S}$ values during winter and spring, while the 


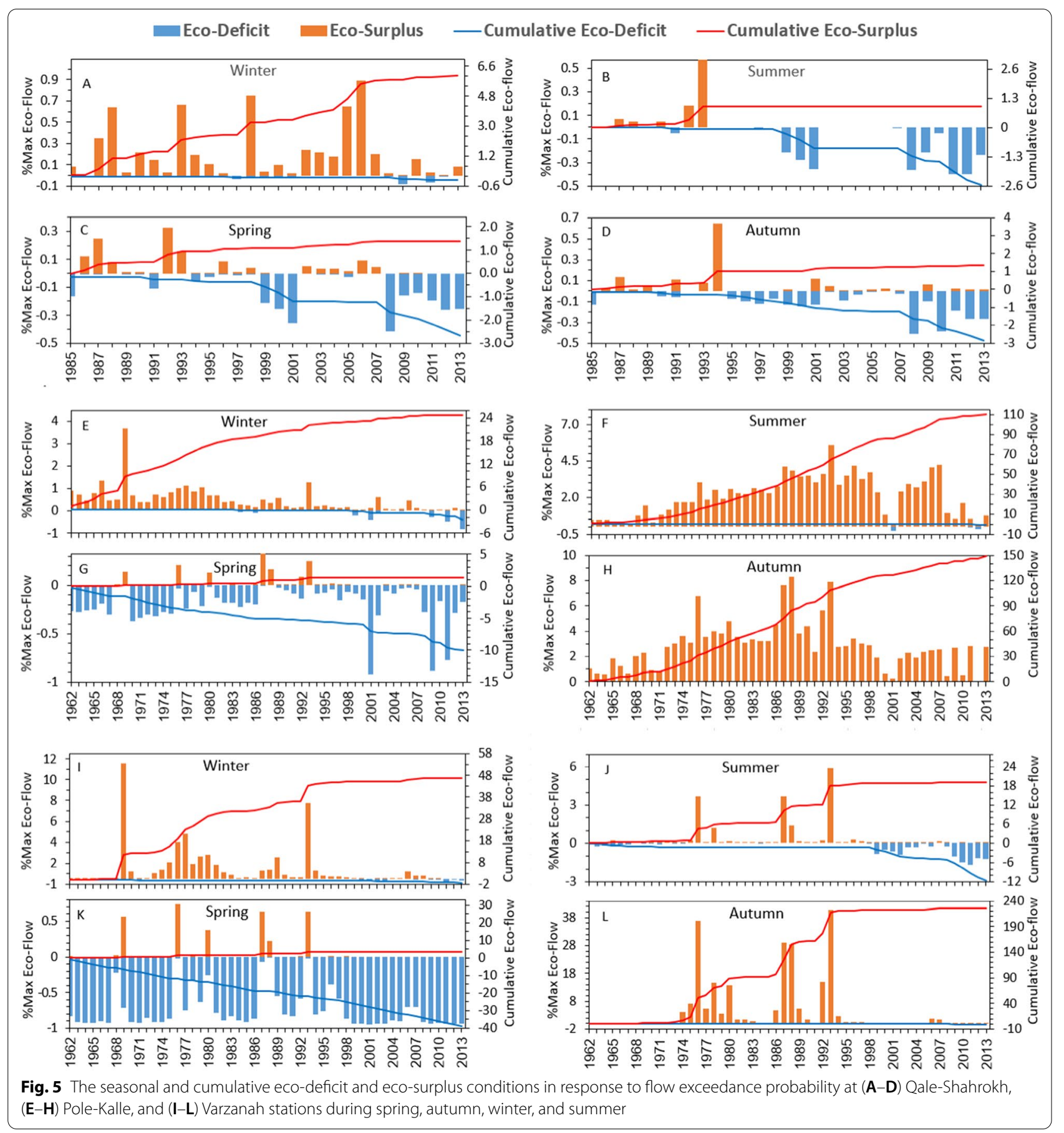

opposite was true during summer and autumn. In PoleKalle station, $79 \%, 5 \%, 93 \%$, and $100 \%$ of years showed zero $\mathrm{ED}_{S}$ values, implying the significant impact of damming on the $\mathrm{ED}_{S}$ improvement in spring and its reduction in other seasons. Another feature in Pole-Kalle station is the continuous non-zero, although small, summer and autumn $\mathrm{ES}_{S}$ values during the whole period (1962-2013), implying the positive effect of the Zayandeh-Rud dam on summer and autumn ecohydrological conditions. A look into the summer and autumn $\mathrm{ES}_{S}$ graphs in the upstream station (Qale-Shahrokh) confirms such implication, as in a part of the study period that overlaps, a large number of months have zero values.

In Varzanah station, non-zero $\mathrm{ES}_{S}$ values occurred mainly during the post-dam period, while near-zero and zero $\mathrm{ES}_{S}$ values occurred mainly during the pre-dam 
(1962-1968) and the post-dam period (1994-2013). In the Varzanah terminal station, $\mathrm{ED}_{S}$ values were more amplified, especially during spring and summer. In winter, the absolute $\mathrm{ED}_{S}$ values were minuscule. It implies that damming increased the absolute $\mathrm{ED}_{\mathrm{S}}$ during spring and also the $\mathrm{ES}_{S}$ during summer and autumn. The continuous non-zero spring and zero autumns $\mathrm{ED}_{S}$ values that occurred during the post-dam period imply the significant negative and positive impact of the Zayandeh-Rud dam, respectively. To evaluate the overall characteristics of ES and ED during the pre-dam (1962-1971) and postdam periods (1972-2013) and to interpret the interannual variation during each stage, the cumulative eco-flow graphs are used (Fig. 5; blue and red lines).

In the cumulative $\mathrm{ES}_{S}$ curves (Fig. 5, red line), the very steep line segment indicates that the $\mathrm{ES}_{S}$ at the right endpoint is much greater than the left endpoint. A horizontal line segment illustrates that the $\mathrm{ES}_{S}$ at the right endpoint is zero. The cumulative $\mathrm{ED}_{S}$ curves have similar implications, which in addition to interannual variation, the slope of the curves in each stage reveals the influence of the dam. In Pole-Kalle station, the cumulative summer and autumn $\mathrm{ES}_{S}$ curves ascended fast during the postdam period. In spring, the cumulative $\mathrm{ES}_{S}$ curve became almost horizontal during the study period. At Varzanah station, the $\mathrm{ES}_{S}$ curve of winter, summer, and autumn ascends fast during the post-dam period until 1994, then becomes relatively horizontal. It implies a substantial negative impact of the Zayandeh-Rud dam by increasing the $\mathrm{ES}_{S}$ in winter, summer, and autumn and further increasing $\mathrm{ED}_{S}$ in spring.

\section{The modeled Shannon diversity index}

Figure 6 shows the temporal variation of the modeled Shannon diversity index and the annual eco-flows. Based on the Spearman correlation coefficient at 0.05 significance level, the correlation between annual ES and ED with the Shannon diversity index is significant through the river basin. Pearson's $r$ of the annual ES in QaleShahrokh, Pole-Kalle, and Varzanah stations are 0.79 with $P<0.00001,0.55$ with $P<0.00001$, and 0.49 with $P=0.0002$, respectively. Accordingly, Pearson's $r$ of the annual ED in the aforementioned stations are 0.52 with $P=0.004,0.42$ with $P=0.002$, and 0.39 with $P=0.004$, respectively. These results indicate that Pearson's $r$ of the annual ES is much larger than Pearson's $r$ of the annual ED. So, the interannual variation of ES and the Shannon diversity index mimics similar patterns (Fig. 6A and C). Moreover, the riverine ecological diversity is more sensitive to floods than hydrological droughts.

In Qale-Shahrokh station, Spearman correlation coefficients between the Shannon diversity index and $\mathrm{ES}_{S}$ are 0.58 with $P=0.001,0.39$ with $P=0.0355,0.82$ with $P<0.001$, and 0.17 with $P=0.37$ for winter, spring,
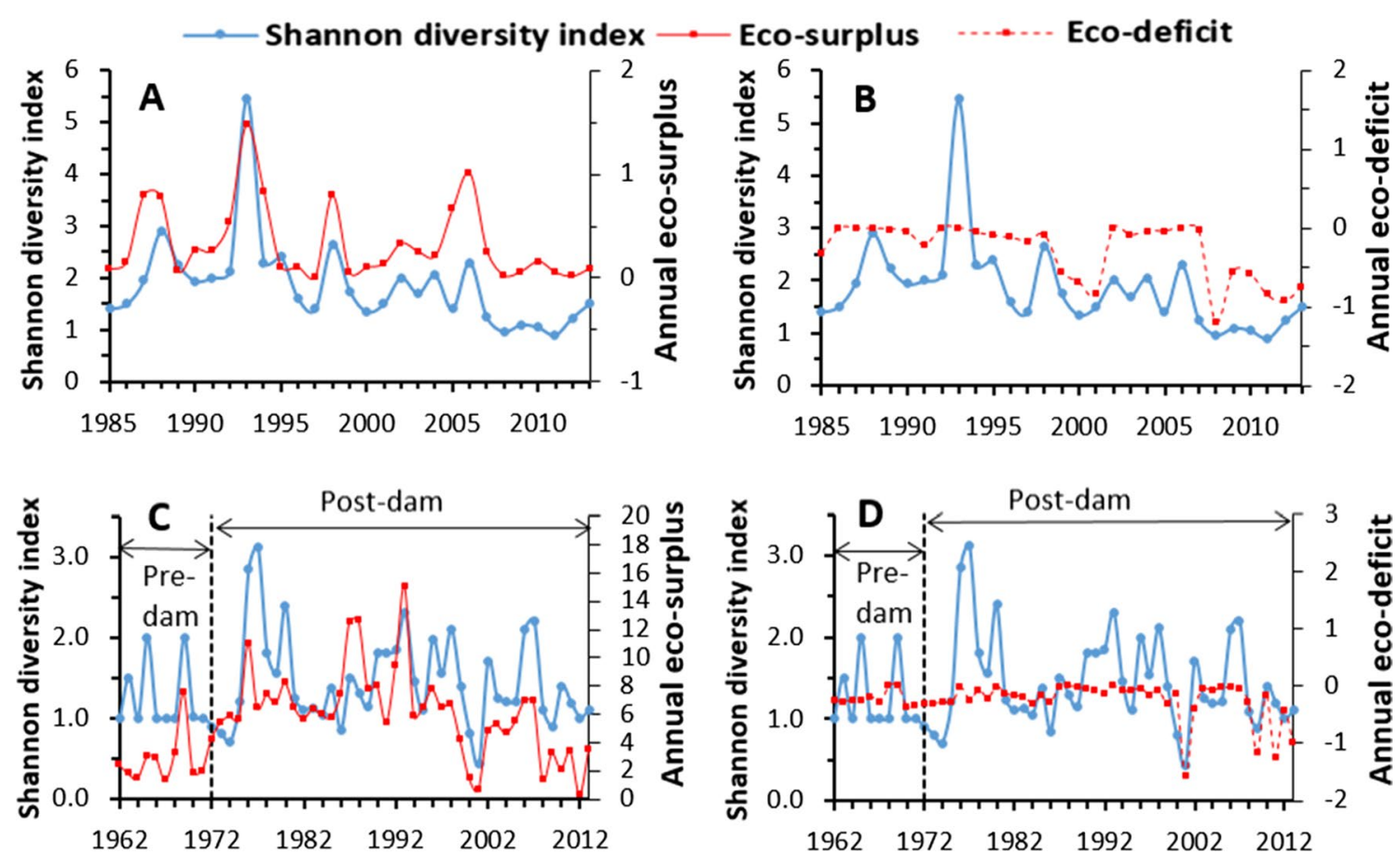

Fig. 6 The variation of modeled Shannon diversity index and annual eco-flows determined by discharge hydrographs in Qale-Shahrokh station (A, B) and Pole-Kalle station (C, D) 
summer, and autumn, respectively. The corresponding values for $E D_{S}$ are 0.31 with $P=0.1,0.46$ with $P=0.012$, 0.44 with $P=0.016$, and 0.51 with $P=0.004$, respectively. Overall, Guo's method performs well in the study basin. The summer $E S_{S}$ and autumn $E D_{S}$ have a significant Pearson's $r$ ( 0.82 versus 0.51 with $P<0.005)$. Therefore, there is a significant correlation between the summer $E S_{S}$ and autumn $E D_{S}$ with the Shannon diversity index. Furthermore, riverine ecological diversity is more sensitive to summer floods and autumn hydrological droughts than other conditions in the pre-dam period. Damming altered the hydrological regimes and subsequently impacted the ecosystem. Figure 6 shows the Shannon diversity index and the annual ED and ES during the predam and post-dam stages. After the completion of the Zayandeh-Rud dam, the Shannon diversity index relative to the pre-dam stage (until 1972) increased more rapidly (during 1973-2013). However, after the hydrological drought period began, the Shannon diversity index dropped more quickly.

\section{Discussion}

Calibration and validation of SWAT were generally satisfactory (all Nash-Sutcliffe efficiency coefficients were above 0.51 , and all coefficients of determination were above 0.62 ) as presented in the recent paper by Zolfagharpour et al. (2020) (see Additional file 1: Fig. S1). The sensitivity analysis of the streamflow in the ZayandehRud River demonstrated that the model had the highest sensitivity to effective hydraulic conductivity in the main channel alluvium, Manning's " $n$ " value for the main channel, and available water capacity of the soil layer, respectively (Zolfagharpour et al. 2020).

The results indicated that the mean monthly flow over the NFR and post-impact periods decreased over April to January at Qale-Shahrokh station, April to June at Eskandari, Pole-Zamankhan, Musian, and Varzanah stations, and April and May at Pole-Kalle station. However, the average monthly flow increased during July to March, at Eskandari, Pole-Zamankhan, Musian, and Varzanah stations, during June to March at Pole-Kalle station, and during February to March at Qale-Shahrokh station. There is a significant rising trend in the mean monthly flow during the low-flow months relative to the preimpact period. Moreover, the alterations at Qale-Shahrokh station in February, August, October, and December were in the range of low alteration. This station experienced moderate alteration in June and September. Also, there was a high alteration in March and July at Varzanah station and June at Eskandari station. The IHA group 1 altered negatively in $60 \%$ of the cases under the impact of climate variability, with the most significant alteration in November.
The impacts of the human activity and climate variability were substantial and minor, respectively, on ecologically relevant flows within the study basin. For example, the climate variability slightly increased the maximum monthly streamflow, especially during March, June, July, and November. With the current severity of climate variability, the future climate condition is anticipated to influence 1- to 90-day maximum flows, date of minimum, low pulse duration, and IHA group 5 more severely. On the other hand, the human activity caused a significant decrease in 1- to 90-day maximum flows, increasing/ decreasing pattern in the date of minimum/maximum, the rise and fall rates, and the number of reversals of streamflow. Downstream of the dam, the extreme maximum flows on average decreased more than the mean net increase/decrease in the extreme minimum flows. It is due to a considerable increase in the release by Zayandeh-Rud dam. For example, the Zayandeh-Rud dam operation increased the minimum 1-day flow by 0.574 $\mathrm{MCM}$ and reduced the maximum 1-day flow by 11.863 MCM at Pole-Zamankhan station.

Comparing the cumulative eco-flow curves of the upstream station (Qale-Shahrokh) with the first downstream station (Pole-Kalle) implies that the ZayandehRud dam impacted the ES and ED more severely than hydrological droughts did. Zolfagharpour et al. (2021), using the standardized hydrological drought index showed that the drought occurred in the study basin from 1985 to 1986, 1991, 1997, 1999 to 2001, and 2008 to 2013. In addition, they indicated the most frequently occurring drought has been mild, and the basin has experienced its most severe droughts in 1997, 2001, 2008, 2009, and 2011. The most transparent feature of the cumulative $\mathrm{ES}_{S}$ curves is the horizontal pattern after 1995, a period with mild-to-severe long-term hydrological drought spells. Assessment of the ES values during summer and autumn shows that the reservoir intensified the rise rate (Fig. 5G, $\mathrm{H}, \mathrm{K}, \mathrm{L}$ ), implying damming had an amplifying effect during these seasons, while the reservoir restored the summer ecohydrological conditions. For the summer and autumn $\mathrm{ED}_{S}$, the Zayandeh-Rud dam severely decreased the rise rate and reset the deficit to zero, implying a positive effect of the reservoir in these seasons. For the spring and winter $\mathrm{ED}_{S}$ values, the Zayandeh-Rud dam, however, slightly increased the rise rate, implying that it had an adverse effect in these two seasons.

Sustaining natural streamflow criteria is indispensable to preserve the downstream reaches and maximize the ecological health of the Gavkhuni terminal wetland located downstream of Varzanah station. The reduced inflow and high hydrologic alterations induced by the Zayandeh-Rud dam threaten the shrinking Marsh and consequently the minimum health and reproduction 
condition of Artemia. Moreover, the dam impacts the population and survival of other fauna and some terrestrial species (such as flamingo, Phoenicopterus ruber roseus) that feed on Artemia. In almost all study stations, the influence of hydrologic alteration was negative in May and similarly in all stations, except Pole-Kalle, in June. Hence the primary spawning season (May-June) for Petroleuciscus esfahani and Capoeta damascina (a native cyprinid) along the Zayandeh-Rud River (Asadollah et al. 2011), and the spawning period (April-July) for Aphanius isfahanensis (Keivany 2013), are dependent on the natural flow variability. The dam intercepts floodwaters, hence, reduce peak flows that occur in April and May. While the growth period peaks between May and June (Asadollah et al. 2011), the natural land cover species may be negatively influenced by the altered flow leading to the possible extinction of fauna along the Zayandeh-Rud River. In contrast, the climate variability would slightly impact the streamflow during May to June period. Thus, the species spawning would not be affected. Overall, there is a need for long-term monitoring of fish populations to understand their response to hydrological changes for effective resource management in the Zayandeh-Rud River.

Figure 6A and $\mathrm{C}$ shows a similar pattern between the modeled Shannon diversity index and the annual ES during all times. From the ecosystem point of view, this indicates the apparent causality between the annual ES and Shannon diversity index and shows that the impact of $\mathrm{ES}_{S}$ on the diversity of ecosystems is more significant than that of the $\mathrm{ED}_{S}$. Guo et al. (2021) indicated that the correlation between ED and Shannon diversity index was significant with similar trend patterns, and this study supports their conclusion on the causality between the eco-flows and Shannon diversity index. When the ecosystem suffers from water scarcity, the diversity of the ecosystem will be adversely affected.

The reservoir and hydrological droughts have different effects with different magnitudes on the Shannon diversity index. The analysis of the upstream part of the basin showed that hydrological drought events slightly impacted the Shannon diversity index and eco-flow characteristics (Fig. 6A, B). On the contrary, the dam's downstream station (Pole-Kalle) showed quite a different pattern (Fig. 6C, D), attributed to reservoir regulated flow. One period of intense hydrological drought caused hydrologically dry periods during 1971, while three periods of low flow during 1974-1975, 1990-1991, and 2001-2002 water years appeared to be connected to severe hydrological drought (Sarhadi and Soltani 2013). It caused insufficiency in satisfying the instream flow requirement, which is not entirely due to reservoir regulation.
Upstream of the study basin tends to receive high seasonal precipitation in spring. On the other hand, downstream areas generally receive low rainfall and have no significant contribution to the streamflow. ZayandehRud dam has been primarily operated to supply irrigation and domestic water consumption. As agricultural land development continuously expanded, the hydrologic regimes upstream and downstream of Zayandeh-Rud dam were greatly influenced. Increased land cover is generally expected to reduce the river runoff ( $\mathrm{Li}$ et al. 2007; Saghafian et al. 2008).

In addition, the response of the downstream areas depends on reservoir regulation during wet and dry seasons. For example, the Zayandeh-Rud dam releases more water during the August to February period, resulting in the increase of low downstream flows (especially extreme minimum flow) at Pole-Zamankhan, Pole-Kalle, Musian, and Varzanah stations. On the other hand, during dry periods, the dam operator closes the gates, and consequently, the flow during the post-impact period may even reach zero in downstream areas. Therefore, the impact of the Zayandeh-Rud dam on the flow regime is quite significant. Nonetheless, in upstream hydrometric stations, the DFA varied considerably. The only stations that recorded moderate alterations were Eskandari and Qale-Shahrokh, with a degree of $66.5 \%$ and $50.7 \%$, respectively.

At Eskandari station, the median flow in the natural state in January, August, and October to December was only $0.02 \mathrm{MCM}$. The Cheshmeh-Langan interbasin water transfer increased the flow in the aforementioned months to $7.63,0.19,2.84,5.86$, and $7.63 \mathrm{MCM}$, respectively, causing deviations up to 379 times. Although Qale-Shahrokh station is the most upstream hydrometric station and receives additional water from three interbasin water transfer projects, the median flow in this station varied from 51.2 to 75 MCM. Furthermore, excessive agricultural water consumption decreased the median flow to a range of 35.8 to $59.7 \mathrm{MCM}$, causing deviations up to 35 times. Again, at Pole-Zamankhan station located downstream of the dam, the median flow was altered from 3.4 to $13.9 \mathrm{MCM}$, whereas impoundment by Zayandeh-Rud dam increased the flow to a range of 95.1-180 MCM, causing deviations up to 49.6 times.

Most stations recorded a reduction in low pulse duration, high pulse number, high pulse duration, rise and fall rates, and an increase in low pulse number and number of reversals. Such patterns were primarily due to regulated reservoir operation, including storing and releasing flows partly aimed at flood control or hydroelectric generation, thus altering river natural characteristics and pulse behavior. However, due to the variation of water consumption across the Zayandeh-Rud Basin, the alteration patterns are not similar in all stations. Zayandeh-Rud 
dam is a regulated reservoir that can store water during wet years to be used in dry years. This type of regulation has different impacts on downstream flow timing, pulse behavior, change rate, and frequency. All downstream stations responded by overall high hydrologic alteration such that the human activity resulted in low (14\%), moderate (28\%), and severe (58\%) alterations in the IHA parameters of groups 3,4 , and 5 , respectively, based on the RVA target $(0-33 \%, 34-67 \%$ or $>67 \%)$. Also, the climate variability impacted $78 \%, 8 \%$, and $14 \%$ of the IHA parameters of groups 3,4 , and 5 , with low, moderate, and severe alteration, respectively.

Numerous factors contributed to the spatial differences in the degree of hydrologic alteration. In this regard, the operational targets of the reservoir determine the regulation mode, which influences the reservoir's capacity to alter hydrologic conditions and environmental components that preserve the environmental flow in the study basin (Zolfagharpour et al. 2021). Although a dam alters the hydrological characteristics, reconsidering reservoir operation rules may alleviate negative consequences (Zolfagharpour et al. 2020, 2021).

\section{Management implications}

Human-induced streamflow alteration should be reduced to preserve the ecological condition of the Gavkhuni Marsh. Reservoir operations can best allocate the downstream demands and maintain high degrees of biological diversity and integrity that ensure the good health of the river ecosystem (Zolfagharpour et al. 2021). The streamflow characteristics at upstream stations satisfy the surface water quality standards by maintaining the minimum required environmental flow (Zolfagharpour et al. 2021), so aquatic organisms are minimally affected by water pollution. In contrast, the downstream stations are severely affected by the reservoir operation (Fig. 4) and the inflow of sewage and various polluting substances, especially near Zarrinshahr (Keivany 2013). During hydrological droughts (e.g., from 1985 to 1986, 1991, 1997, 1999 to 2001, and 2008 to 2013), the untreated sewage of industries may cause unrecoverable damages to the Gavkhuni Marsh ecosystem. A good measure to avoid such conditions is to follow the recommended policies reported by Zolfagharpour et al. (2021) to improve the quality of streamflow, reduce pollution, and increase the self-purification capacity of the river. It may be achieved by maintaining minimum streamflow of $4.25 \mathrm{~m}^{3} / \mathrm{s}$ in the Varzanah station (Hekmatpanah et al. 2012). Zolfagharpour et al. (2021) estimated the eco-flow of the Marsh equal to $281.5 \mathrm{MCM}$, which could be allocated through updating reservoir operation policy. This eco-flow (281.5 $\mathrm{MCM}$ /year) is at least twofold of the minimum required streamflow (134 MCM/year), estimated by Hekmatpanah et al. (2012), for maintaining the standard water quality of Gavkhuni Marsh.

However, not all changes and alterations are reversible and not all species may be preserved. Climate change, in conjunction with irreversible human alterations over the landscape, may disrupt the restoration efforts to return the Gavkhuni Marsh to its past condition. Commonly, traditional management practices are based on the assumption of stable climatic conditions. Although the effects of climate drivers on flow alteration (see Additional file 1: Table S2, and Fig. S2) are minor and can be offset by modifying the reservoir policies, global warming influences river flow temperature, which could be detrimental to many species survival (Hekmatpanah et al. 2012). For restoration under climate change, it is essential to reduce ecosystem vulnerability and promote adaptation and resilience. For example, managing resilience may include: reducing anthropogenic stressors (Zolfagharpour et al. 2021), protecting key ecosystem features (Zolfagharpour et al. 2021; Hekmatpanah et al. 2012), and implementing mitigation practices to control substantial ecosystem change.

\section{Conclusions}

The results of this study have implications for environmental protection strategies and improving the sustainability of the ecosystem. The study basin has been under pressure from water overconsumption, lack of attention to the eco-flow, and the flow regulations imposed on the Zayandeh-Rud River. Evaluation of hydrologic alteration is key for maintaining the primary role and function as well as the resilience of a riverine ecosystem. The following conclusions may be drawn from the study:

1. Zayandeh-Rud dam significantly altered the NFR and the corresponding hydrological indicators downstream, mainly the frequency of expected median flows reduced in four out of six stations. In contrast, although climate variability caused low alteration in the NFR (80\% of parameters have an alteration of $0-33 \%$, with the tiniest alteration in IHA group 1), its direct effects, including global warming that rises water temperature, may endanger the aquatic species, especially endemic ones. So, it may exacerbate/ overcomplicate management decisions and impose an aggregated impact on river species.

2. The upstream areas of the dam experienced low alteration, while the modeled Shannon diversity index showed no significant changes. So the taxa of the upstream seem to be partly protected against severe disturbances. The hydrologic alteration in monthly and seasonal high-flows decreased in downstream areas, highlighting the bold impact of the Zayandeh- 
Rud dam in long-term operation that may threaten life-cycle requirements of the aquatic species.

3. The eco-flow metrics based on discharge hydrographs are effective to assess the ecological diversity of the ecosystem. The modeled Shannon diversity index showed a stronger correlation to the summer $\mathrm{ES}_{S}$ and autumn $\mathrm{ED}_{S}$.

Climate variability impacts, however minor, consist of two components: one is the indirect effect on river flow alteration, and the other is the direct effect on flow temperature. The first may be managed by updating reservoir operation rules as described by Zolfagharpour et al. (2021). The second component is inevitable which can greatly affect the ecosystem and especially the endemic fish species. Proper reservoir operation minimally impacts the ecosystem, so that the endemic species have sufficient time to adapt to the new ecological system. Also, establishing clear regulations to decrease water over-extraction, an ongoing challenge among water authorities, can uphold the DHA in upstream areas.

\section{Abbreviations}

DHA: Degree of hydrologic alteration; IHA: Indicators of hydrologic alteration; RVA: Range of variability approach; NFR: Natural flow regime; SWAT: Soil and water assessment tool; FDC: Flow duration curve; SWAT-CUP: SWAT calibration and uncertainty package; ZRRB: Zayandeh-Rud River Basin; DFA: Overall degree of flow alteration; MCM: Million cubic meters.

\section{Supplementary Information}

The online version contains supplementary material available at https://doi. org/10.1186/s13717-022-00362-4.

Additional file 1: SWAT calibration and verification results, Summary of Indicators of Hydrologic Alteration variables, Additional Tables, and Additional Figures considering the impact of climate variability.

\section{Acknowledgements}

The authors acknowledge Isfahan Water Authority and Isfahan Department of Environment in Iran for providing flow data and other study basin information.

\section{Authors' contributions}

FZ designed, analyzed, interpreted, and drafted the manuscript. BS supervised the designed study and contributed to the revision of the first draft. MD contributed to the SWAT model calibration and validation. All authors have read and approved the final manuscript.

\section{Funding}

Not applicable.

\section{Availability of data and materials}

The datasets used and/or analyzed during the current study are available from the corresponding author on reasonable request.

\section{Declarations}

Ethics approval and consent to participate Not applicable.
Consent for publication

Not applicable.

\section{Competing interests}

The authors declare that they have no competing interests.

\section{Author details}

${ }^{1}$ Department of Civil Engineering, Science and Research Branch, Islamic Azad University, Tehran, Iran. ${ }^{2}$ Department of Water Resources Engineering, Tarbiat Modares University, Tehran, Iran.

Received: 13 July 2021 Accepted: 19 January 2022

Published online: 05 February 2022

\section{References}

Arnold JG, Srinivasan R, Muttiah RS, Williams JR (1998) Large area hydrologic modeling and assessment - part I: model development. J Am Water Resour Assoc 34(1):73-89

Asadollah S, Soofiani NM, Keivany Y, Shadkhast M (2011) Reproduction of Capoeta damascina (Valenciennes, 1842), a cyprinid fish, in ZayandehRoud River, Iran. J Appl Ichthyol 27(4):1061-1066

Coad BW, Bogutskaya NG (2010) Petroleuciscus esfahani, a new species of fish from central Iran (Actinopterygii: Cyprinidae). Zootaxa 2534(1):37-47

Dong Q, Fang D, Zuo J, Wang Y (2019) Hydrological alteration of the upper Yangtze River and its possible links with large-scale climate indices. Hydrol Res 50(4):1120-1137

Dosdogru F, Kalin L, Wang R, Yen H (2020) Potential impacts of land use/cover and climate changes on ecologically relevant flows. J Hydrol 584:124654

Gao B, Yang D, Zhao T, Yang H (2012) Changes in the eco-flow metrics of the Upper Yangtze River from 1961 to 2008. J Hydrol 448:30-38

Ghaith M, Li Z (2020) Propagation of parameter uncertainty in SWAT: a probabilistic forecasting method based on polynomial chaos expansion and machine learning. J Hydrol 586:124854

Guo X, Guo Y, Xu L, Deng Y, Yang C (2021) A framework for evaluating the impacts of reservoirs on seasonal ecohydrological conditions based on new eco-flows. Ecohydrology 14:e2293

Hekmatpanah M, Nasri M, Sardu FS (2012) Effect of industrial and agricultural pollutants on the sustainability of Gavkhuni lagoon wetland ecosystem. Afr J Agric Res 7(20):3049-3059

Keivany Y (2013) Threatened fishes of the world: Aphanius isfahanensis Hrbek, Keivany \& Coad, 2006 (Cyprinodontidae). Aqua 19(2):67-70

Li KY, Coe MT, Ramankutty N, De Jong R (2007) Modeling the hydrological impact of land-use change in West Africa. J Hydrol 337(3-4):258-268

Pettersson M (1998) Monitoring a freshwater fish population: statistical surveillance of biodiversity. Environmetrics 9(2):139-150

Pielou EC (1975) Ecological diversity. John Wiley and Sons, New York

Reichold L, Zechman EM, Brill ED, Holmes H (2010) Simulation-optimization framework to support sustainable watershed development by mimicking the predevelopment flow regime. J Water Resour Plan Manag 136(3):366-375

Richter B, Baumgartner J, Wigington R, Braun D (1997) How much water does a river need? Freshw Biol 37(1):231-249

Saghafian B, Farazjoo H, Bozorgy B, Yazdandoost F (2008) Flood intensification due to changes in land use. Water Resour Manag 22(8):1051-1067

Sarhadi A, Soltani S (2013) Determination of water requirements of the Gavkhuni wetland, Iran: a hydrological approach. J Arid Environ 98:27-40

Shannon CE (1948) The mathematical theory of communication. Bell Syst Tech J 27:379-423, 623-656

Sharma PJ, Patel PL, Jothiprakash V (2021) Impact assessment of Hathnur reservoir on hydrological regimes of Tapi River, India. ISH J Hydraulic Eng 27:433-445

Singh RK, Jain MK (2021) Reappraisal of hydrologic alterations in the Roanoke River basin using extended data and improved RVA method. Int J Environ Sci Technol 18:417-440

Song X, Zhuang Y, Wang X, Li E, Zhang Y, Lu X, Yang J, Liu X (2020) Analysis of hydrologic regime changes caused by Dams in China. J Hydrol Eng 25(4):05020003 
Sun G (2013) Impacts of climate change and variability on water resources in the Southeast USA. In: Climate of the Southeast United States. Island Press, Washington, DC, pp 210-236

Sun G, Hallema D, Asbjornsen H (2017) Ecohydrological processes and ecosystem services in the Anthropocene: a review. Ecol Process 6:35

Usman M, Pan X, Penna D, Ahmad B (2021) Hydrologic alteration and potential ecosystem implications under a changing climate in the Chitral River, Hindukush region, Pakistan. J Water Clim Change 12(5):1471-1486

Vogel RM, Sieber J, Archfield SA, Smith MP, Apse CD, Huber-Lee A (2007) Relations among storage, yield, and instream flow. Water Resour Res 43(5):W05403

Yang YC, Cai X, Herricks EE (2008) Identification of hydrologic indicators related to fish diversity and abundance: a data mining approach for fish community analysis. Water Resour Res 44(4):W04412

Zhang Z, Liu J, Huang J (2020) Hydrologic impacts of cascade dams in a small headwater watershed under climate variability. J Hydrol 590:125426

Zolfagharpour F, Saghafian B, Delavar M (2020) The impacts of climate variability and human activities on streamflow change at basin scale. Water Supply 20(3):889-899

Zolfagharpour F, Saghafian B, Delavar M (2021) Adapting reservoir operation rules to hydrological drought state and environmental flow requirements. J Hydrol 600:126581

Zuo QI, Liang SH (2015) Effects of dams on river flow regime based on IHA/ RVA. Proc Int Assoc Hydrol Sci 368:275-280

\section{Publisher's Note}

Springer Nature remains neutral with regard to jurisdictional claims in published maps and institutional affiliations.

\section{Submit your manuscript to a SpringerOpen ${ }^{\odot}$ journal and benefit from:}

- Convenient online submission

- Rigorous peer review

- Open access: articles freely available online

- High visibility within the field

- Retaining the copyright to your article

Submit your next manuscript at $\boldsymbol{\nabla}$ springeropen.com 